\title{
Postoperative Management of K-Wires in Percutaneous Foot Surgery
}

\author{
Arzac Ulla Ignacio* \\ BR Traumatologia, Azul Buenos Aires, Argentina
}

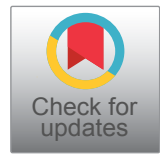

*Corresponding author: Arzac Ulla Ignacio BR Traumatologia, Azul Buenos Aires, Argentina, Tel: 00542281-522127

\begin{abstract}
Introduction: When a Kirschner wire (K-wire) is used percutaneously, the protruding end often causes discomfort and is associated with an increased risk of complications, such as pin loosening, infection, injury, etc. This study was undertaken to determine the ideal postoperative management when using these implants. We describe a surgical alternative for K-wire management in foot surgery.
\end{abstract}

Materials and method: A prospective, descriptive study was conducted. A total of 39 patients (70 procedures) were enrolled in the study and underwent K-wire fixation. All pins were cut short and buried in the subcutaneous tissue of the finger until completely hidden beneath the skin. Demographic and clinical variables were analyzed.

Results: The following variables were evaluated: Age, gender, AOFAS score, duration of K-wire stay, antibiotic prophylaxis, diagnosis, previous conditions, pin extrusion and surgical procedure performed. Median duration of K-wire stay was 30 days. All patients were allowed to shower and wet the wound 24 hours following surgery.

Conclusion: The method described in our study is easily performed and does not require special equipment or supplies.

\section{Level of Evidence}

IV

\section{Keywords}

K-wire, Kirschner, Percutaneous, Postoperative management

\section{Introduction}

Introduced by Martin Kirschner, in 1909, Kirschner wires (K-wires) are extensively used in orthopedics in bone fixation procedures. They are reliable, easily acquired, and inexpensive [1,2].
Complications associated with the use of K-wires include infection, pin loosening, pin migration, and loss of reduction, among others $[1,3,4]$. K-wire sites are also susceptible to infection because the skin barrier has been disrupted. These mild infections can be treated by improving wound cleansing and administering short courses of oral antibiotics [5]. Severe complications, such as deep tissue infection and osteomyelitis, may occur in up to $4 \%$ of cases $[6,7]$.

When a percutaneous K-wire is used in foot surgery, such as to stabilize the first metatarsal when using the Bosch technique or in interpositional arthrodesis/arthroplasty of the interphalangeal joint for hammer or mallet toe deformity correction, the protruding end causes discomfort and is associated with risk of migration, dislodgement, breakage, infection, pain, etc.

Several techniques have been used to prevent accidental pin dislodgement, including bending the K-wires into various shapes and covering the exposed end with different materials, such as adhesive tape, corks, rubber stoppers, epoxy putty, and plastic balls. These temporary solutions have several disadvantages, including patient discomfort, increased pin volume, skin irritation and a higher infection rate, and are not actually completely effective in preventing pin extrusion.

Permanent implants, including cannulated screws, headless compression screws, and conical screws, can now be used for osteotomy fixation in percutaneous hallux valgus surgery, and intramedullary implants, bioabsorbable pins, etc. for interphalangeal arthrodesis of the lesser toes. However, there is no evidence to support the superior performance of these implants over

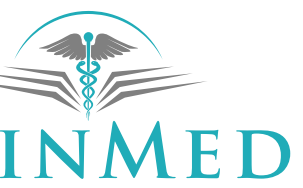

INTERNATIONAL LIBRARY 
K-wires. Besides, due to their high cost, K-wire fixation remains the gold-standard technique.

Based on the above considerations, the aim of this study was to determine the ideal postoperative management of K-wires to prevent complications associated with exposed temporary implants. Our hypothesis is that by cutting the pin at skin level and burying it in the subcutaneous tissue, postoperative comfort is improved without the risk of unwanted extrusion or infection.

\section{Materials and Method}

Between January 2017 and December 2018, 39 adult patients underwent transient K-fixation for the treatment of hallux valgus, hammer toe, overlapping fifth toe and/or tailor's bunion, totaling 70 procedures. All patients were treated by a single foot and ankle orthopedic surgeon.

Inclusion Criteria:

Patients with:

1. Hallux valgus

2. Hammer toe

3. Tailor's bunion

Exclusion criteria included pediatric/skeletally immature patients, active infection, and revision procedures.

Percutaneous Bosch technique with $3 \mathrm{~mm}$ Steinman nails was used to correct hallux valgus deformity.

For overlapping fifth toe correction, Distal Metatarsal Minimal Invasive Osteotomy (DMMO) was performed and osteotomies were fixed with $1.5 \mathrm{~mm} \mathrm{~K}$-wires, as in interphalangeal arthrodesis and tailor's bunion correction.

All pins were cut at skin level and buried in the subcutaneous tissue of the finger until completely hidden beneath the skin (Figure 1).

Antibiotic therapy consisted of a single preoperative dose of IV cephalothin (1g) given 30 minutes prior to incision, followed by oral cephalexin (1g) every 12 hours for an additional 4 days.

After the first postoperative visit (24 hours following surgery), patients were allowed to shower and wet the surgical site, and were advised to clean the wound with regular soap and apply alcohol afterwards. A gauze dressing was applied on the wound for ambulation during the first 10 days. Immediate weight bearing was allowed on a postoperative shoe/sandal, limited by patient tolerance.

All patients underwent radiographic evaluation 24 hours after surgery, on the $21^{\text {st }}$ day upon K-wire removal, and 6, 12 and 18 months following surgery.

Function and pain assessment was also performed 18 months after surgery using the American Orthopedic Foot and Ankle Society (AOFAS) Scale.
The following variables were evaluated: Age, gender, AOFAS score, duration of K-wire stay, antibiotic prophylaxis, diagnosis (hallux valgus, hammer toe, overlapping fifth toe, tailor's bunion), previous conditions (hypertension, hypothyroidism, diabetes, hypercholesterolemia, breast cancer), pin extrusion, type of surgery (PIP arthrodesis, percutaneous osteotomy of the proximal phalanx of the fifth toe, Bosch plus Akin osteotomy, $\mathrm{DMMO})$, post-operative management of the pin, $\mathrm{K}$-wire location and complications.

\section{Statistical analysis}

For quantitative variables, a normality test was performed. If variables followed a normal distribution, mean and standard deviation were used as summary measures. In the event of not following a normal distribution, median and interquartile range were used instead.

Categorical variables were described with their distribution of frequencies and percentages using 95\% confidence intervals. All statistics were analyzed using Statistix 8.0 Chicago statistical package.

\section{Results}

Table 1 shows a summary of treated patient data. A total of 39 patients (mean age 56.11 years) were evaluated, 36 (92.5\%) women and 3 (7.5\%) men (Table 2). Regarding participants' medical history, $10(25 \%)$ patients had hypertension, 6 (15\%) hypothyroidism, 2 (5\%) diabetes, $1(2.5 \%)$ hypercholesterolemia, and $1(2.5 \%)$ had a history of breast cancer.

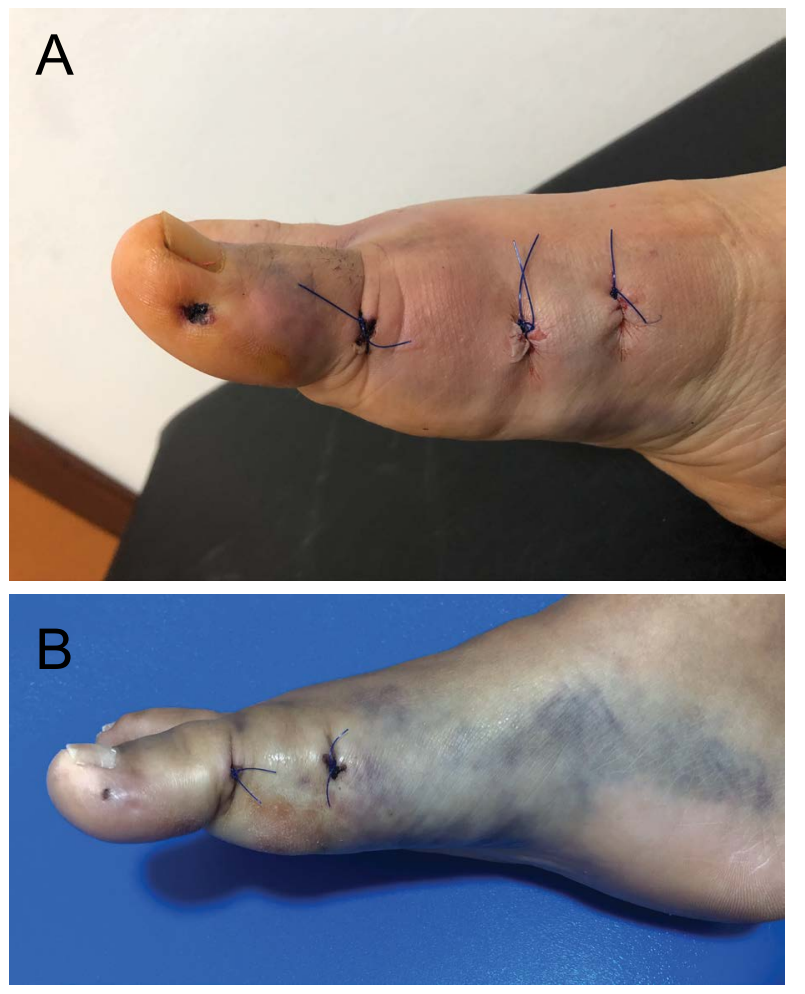

Figure 1: $(A, B)$ Utilización de clavija en tratamiento de hallux valgus. 
Table 1: Variables Studied in k-wire Procedures in Foot Surgery.

\begin{tabular}{|l|l|}
\hline Variables & pacients \\
\hline Number of pacients & 39 \\
\hline Age \pm SD & $56.11 \pm 2.3$ \\
\hline Score AOFAS, \pm SD & $98.17 \pm 0.38$ \\
\hline duration of K-wire stay (days), median (IQ) & $30(I Q 30-31)$ \\
\hline antibiotic prophylaxis (days & 4 (IQ 4-4) \\
\hline
\end{tabular}

Mean and standard deviation (SD), Median. (IQ): Interquartile Range

Table 2: Variables analyzed.

\begin{tabular}{|c|c|}
\hline \multicolumn{2}{|l|}{ N (\%) (IC 95\%) } \\
\hline \multicolumn{2}{|l|}{ Gender } \\
\hline Female & $36(92.5$. IC95\% 84,33\% - 1) \\
\hline Male & $3(7.5 \%$. IC95\% 0\% - 1.69) \\
\hline \multicolumn{2}{|l|}{ Diagnostic } \\
\hline Halux Valgus & $\begin{array}{l}40(57.14 \% . \text { IC } 95 \% 44.83 \% \text { - } \\
69.46 \%)\end{array}$ \\
\hline Hammer Toe & $\begin{array}{l}26(37.14 \% . \text { IC } 95 \% .25 .19 \%- \\
49.17 \%)\end{array}$ \\
\hline Overlapping Fifth Toe & $2(2.85 \%$ IC $95 \% .0 \%-7.4 \%)$ \\
\hline Tailor's Bunion & $2(2.85 \%$ IC $95 \% .0 \%-7.4 \%)$ \\
\hline \multicolumn{2}{|l|}{ Medical History } \\
\hline Hypertension & $10(25 \% \mathrm{Cl} 95 \% .11 .33 \%-39.66 \%)$ \\
\hline Hypothyroidism & $6(15 \% \mathrm{Cl} 95 \% 2.68 \%-27.31 \%)$ \\
\hline Diabetes & $2(5 \% \mathrm{Cl} 95 \% .3 \%-13 \%)$ \\
\hline Hypercholesterolemia & $1(2.5 \% \mathrm{Cl} 95 \% .0 \%-8.58 \%)$ \\
\hline History of breast cancer & $1(2.5 \% \mathrm{Cl} 95 \% .0 \%-8.58 \%)$ \\
\hline Pin extrusion & $2(2.85 \% \mathrm{Cl} 95 \% .0 \%-7.4 \%)$ \\
\hline \multicolumn{2}{|l|}{ Treatment } \\
\hline Arthrodesis & $\begin{array}{l}26(35.71 \% \mathrm{Cl} 95 \% .23,77 \%- \\
47.65 \%)\end{array}$ \\
\hline Akin & $2(2.8 \% \mathrm{Cl} 95 \% .0 \%-7.4 \%)$ \\
\hline Bosh + Akin & 40 (58.57\% Cl 95\%. 46.31-70.82\%) \\
\hline DMMO & $2(2.8 \% \mathrm{Cl} 195 \% .0 \%-7.4 \%)$ \\
\hline \multicolumn{2}{|l|}{ Pin location } \\
\hline $1^{\text {st }}$ toe & $\begin{array}{l}40 \text { (57.14\% Cl 95\%. } 44.83 \% \text { - } \\
69.45 \%)\end{array}$ \\
\hline $2^{\text {nd }}$ toe & $16(22.85 \%$ Cl 95\%. 12.30-33.40) \\
\hline $3^{\text {rd }}$ toe & 7 (10\% Cl 95\%. 2.25-17.74) \\
\hline $4^{\text {th }}$ toe & $3(4.28 \% \mathrm{Cl} 95 \% .0 \%-9.74 \%)$ \\
\hline $5^{\text {th }}$ toe & $4(5.71 \% \mathrm{Cl} 95 \% .0 \%-11.86 \%)$ \\
\hline \multicolumn{2}{|l|}{ Complication } \\
\hline Infections & $2(2.85 \%$ IC $95 \% .0 \%-7.47 \%)$ \\
\hline
\end{tabular}

N (\%) (95\%): Absolute frequency, Percentage, Confidence interval of the $95 \%$.
The most common deformity in patients was hallux valgus $(57 \%)$, followed by hammer toe $(37 \%)$, overlapping fifth toe (3\%) and tailor's bunion (3\%) (Graph 1).

Seventy procedures in which K-wires were inserted percutaneously and buried beneath the skin were included in the study, its use being more frequent in hallux valgus correction (Graph 2). All 70 procedures were performed on an outpatient basis.

Patients were allowed to shower and wet the wound 24 hours after surgery, with a median antibiotic prophylaxis of 4 days.

All patients were clinically evaluated every 7 days until the 30-day postoperative period was completed. At this time point, the K-wire was removed in the operating room, under local anesthesia and without suturing the pin site. Subsequently, patients were evaluated in follow-up visits every 2 months until the first postoperative year was completed, as well as in a final visit 18 months after surgery.

Two of the patients in whom the Bosch technique was used for the treatment of hallux valgus deformity experienced pin extrusion (2.85\%) with superficial infection (none had previous conditions). These patients were treated with oral antibiotics for 10 days and K-wire removal at 24 and 30 days, respectively.

The latter also experienced delayed union, with callus formation 4 months after surgery. There were no complications in the remaining $68(97.14 \%)$ procedures.

In only one procedure $(1.40 \%)$, in which the Bosch percutaneous technique for the treatment of hallux valgus deformity was used, a patient complained of discomfort caused by the K-wire in the postoperative period but stated that he would undergo a similar surgical technique in the future.

The AOFAS score at 18 months was 98.17 .

\section{Discussion}

K-wires are extensively used for fracture, dislocation, osteotomy and arthrodesis fixation in foot surgery since they are easily available, reliable and inexpensive $[1,8]$.

Complications when using this type of fixation include infection, pin loosening, pin migration, fatigue failure and loss of reduction [1,3]. Another drawback when using $\mathrm{K}$-wires is that the protruding end causes soft tissue irritation, pain and discomfort.

Choosing the right pin diameter is vital to ensure sufficient bone stability and prevent potential implant breakage. Pichler, et al. reported K-wire breakage in only 14 cases [9]. Botte, et al. [3] reported an $18 \%$ complication rate, including pin loosening, pin tract infection and pin bending. Neurological complications (16.5\%) have also been reported by Gosens, et al. [10]. In our study, no implant breakage, bending or neurological damage were observed. 


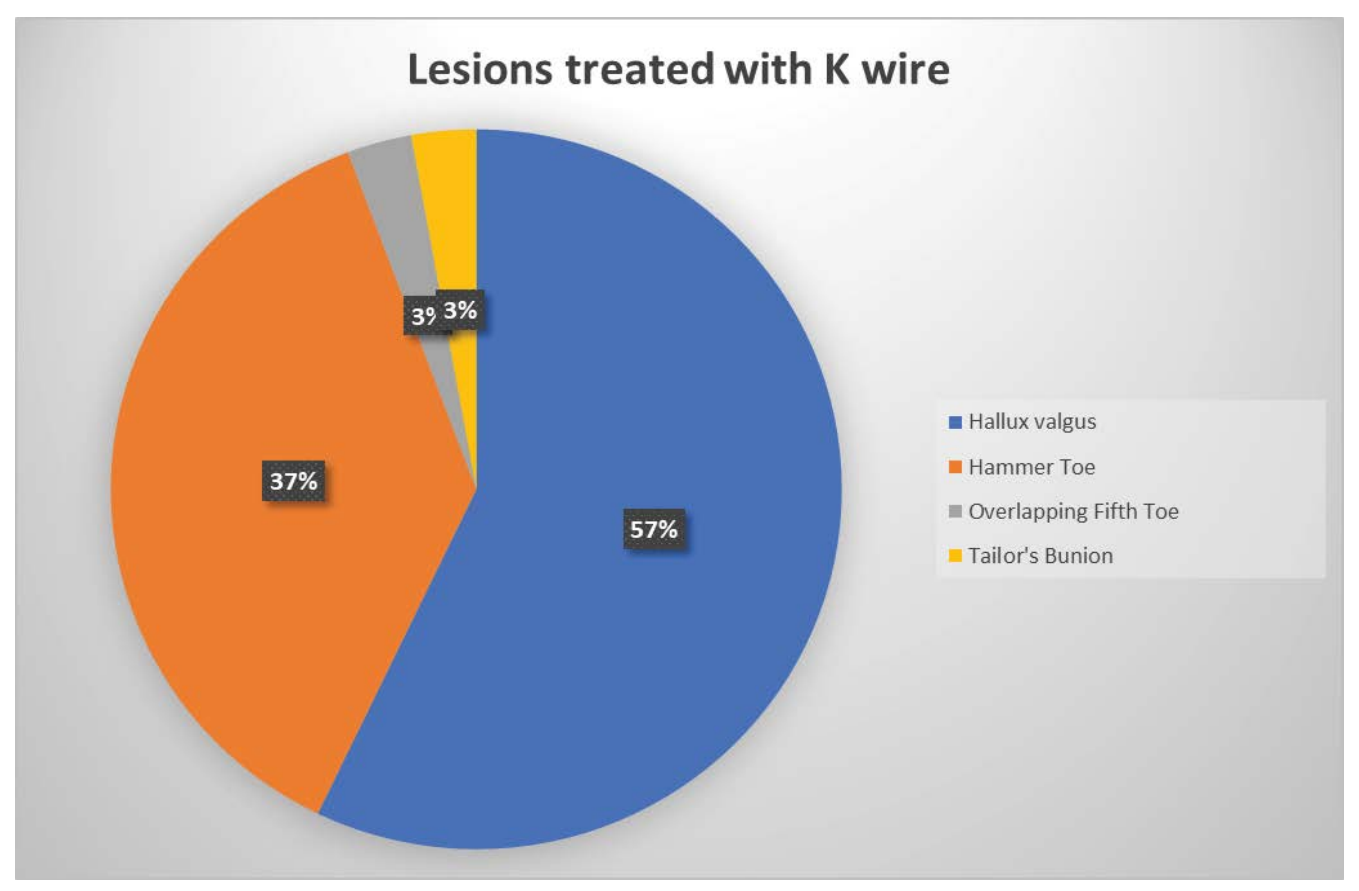

Graph 1: Lesions treated with $\mathrm{K}$ wire.

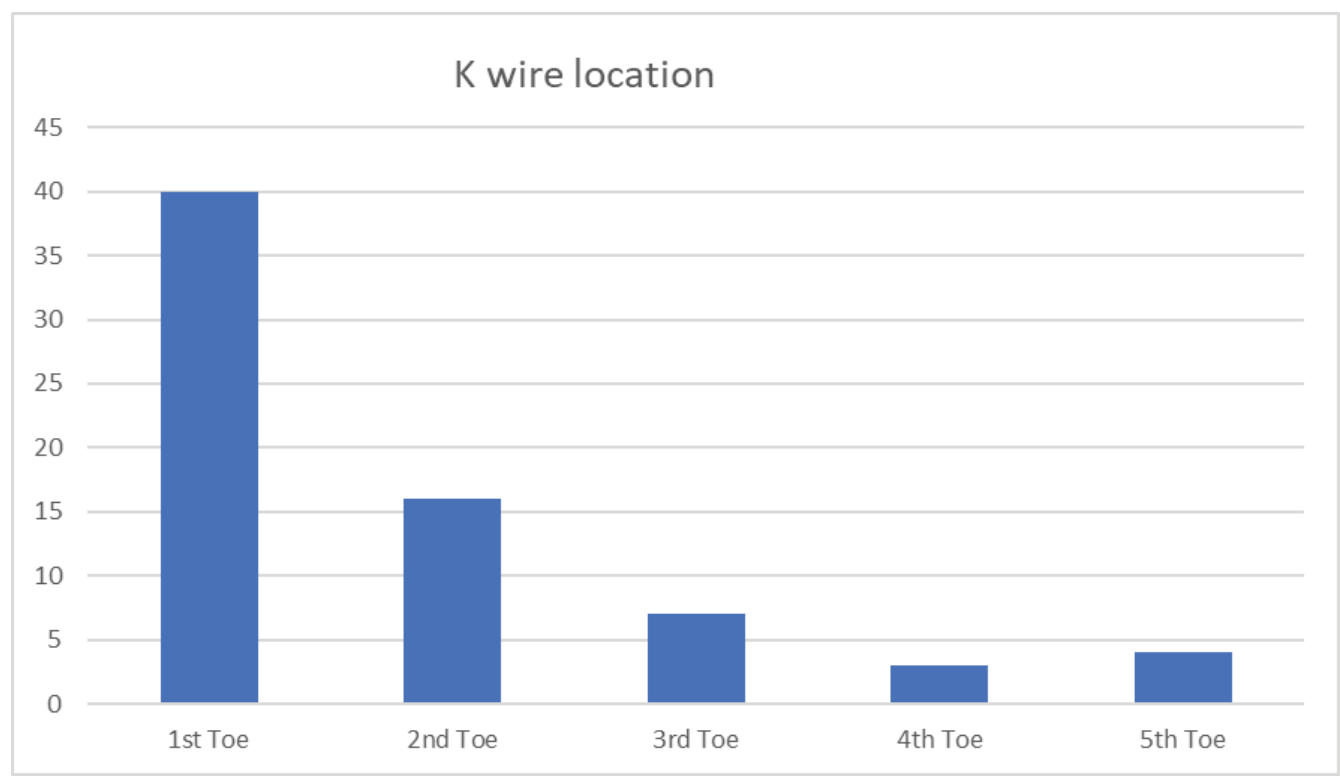

Graph 2: K Wire location.

Concern over the use of K-wires lies with their exposed end and the risk of infection; however, not all cases are susceptible to contamination of the pin entry point [11-15]. Risk factors include advanced age, diabetes, rheumatoid arthritis, collagen diseases, and chronic use of corticosteroids. Another factor which increases the risk of infection is duration of K-wire stay; the longer the implant is used, the higher the infection rate [12]. Gordon, et al. [12] suggested that periarticular fixation is associated with a higher infection rate than diaphyseal fixation ( $4.5 \%$ vs. $1.6 \%)$, possibly due to increased soft tissue movement over the joints. Thicker soft tissue areas on the bone and skin tension around the pin site have also been associated with higher infection rates [15].
There is no consensus on the cleaning method and frequency of the K-wire tip, or on how patients should shower. Some authors recommend not wetting the surgical site, others advise cleansing on a weekly basis while others suggest daily cleansing [12]. In our series, we allowed patients to shower 24 hours after surgery since there is no exposed end of the K-wire and the wound is cleaned with alcohol on a daily basis.

Botte, et al. [3] observed infections in 7\% of patients, implant loosening in $4 \%$, and osteomyelitis in $2 \%$. In their series, Green, et al. [16] reported pin tract infections which required implant removal and fully resolved within 3 months of follow-up. In our study, 2 patients developed superficial infections (2.85\%), which were 
treated with oral antibiotics. Although they resolved without the need of immediate implant removal, one of them experienced delayed union of the Bosch osteotomy, which resolved completely with bone healing within 4 months after surgery and no loss of alignment.

The AOFAS score obtained with our surgical technique was similar to that published in other publications $[17,18]$.

\section{Conclusion}

The use of K-wiring as a fixation method is effective and inexpensive; however, there is no consensus on how to manipulate the implant free ends. The method described in our study is easily performed and does not require special equipment or supplies. Postoperative management of K-wires by burying the protruding end beneath the skin has good aesthetic and functional outcomes, causes less discomfort to the patient and does not increase the infection rate.

\section{Highlights}

- The use of K-wiring as a fixation method is effective and inexpensive.

- Our study reports new way to managefoot post-operative k-wires.

- Postoperative management of K-wires by burying the protruding end beneath the skin has good aesthetic and functional outcomes, causes less discomfort to the patient and does not increase the infection rate.

\section{References}

1. Stahl S, Schwartz, O (2001) Complications of K-wire fixation of fractures and dislocations in the hand and wrist. Arch Orth Traum Surg 121: 527-530.

2. Hong SJ, J Lee H, Kim J, Eo S, Cho S (2013) K-Wire Breakage During Metalware Removal Due to a Defective K-Wire Shaft. Arch Plast Surg 40: 655-657.

3. Botte MJ, Davis JL, Rose BA, Von Schroeder HP, Gellman $\mathrm{H}$, et al. (1992) Complications of smooth pin fixation of fractures and dislocations in the hand and wrist. Clin Orthop Relat Res 194-201.

4. Concannon MJ, Croll GH, Puckett CL (1993) An intraoperative stent for Mclndoe vaginal construction. Plast Reconstr Surg 91: 367-368.
5. Lethaby A, Temple J, Santy J (2013) Pin site care for preventing infections associated with external bone fixators and pins. Cochrane Database Syst Rev 3: CD004551.

6. Green SA, Ripley MJ (1984) Chronic osteomyelitis in pin tracks. J Bone Joint Surg Am 66: 1092-1098.

7. Parameswaran AD, Roberts CS, Seligson D, Voor M (2003) Pin site infection with contemporary external fixation: How much of a problem? J Orthop Trauma 17: 503-507.

8. Firoozabadi R, Kramer P, Benirschke S (2013) Technical Trick: Kirschner Wire Bending. J Orthop Trauma 27: e260-e263

9. Pichler W, Mazzurana P, Clement H, Grechenig S, Mauschitz R, et al. (2008) Frequency of instrument breakage during orthopaedic procedures and its effects on patients. J Bone and Joint Surg Am 90: 2652-2654.

10. Gosens T, Bongers KJ (2003) Neurovascular complications and functional outcome in displaced supracondylar fractures of the humerus in children. Injury $34: 267-273$.

11. Egol KA, Paksima N, Puopolo S, Klugman J, Hiebert R, et al. (2006) Treatment of external fixation pins about the wrist: A prospective, randomized trial. J Bone Joint Surg Am 88: 349-354.

12. Gordon JE, Kelly Hahn J, Carpenter CJ, Schoenecker PL (2000) Pin site care during external fixation in children: Results of a nihilistic approach. J Pediatr Orthop 20: 163-165.

13. Sims M, Saleh M (2000) External fixation-the incidence of pin site infection: A prospective audit. J Orthop Nurs. 4: 5963.

14. Velazquez RJ, Bell DF, Armstrong PF, Babyn P, Tibshirani $\mathrm{R}$ (1993) Complications of use of the llizarov technique in the correction of limb deformities in children. J Bone Joint Surg Am 75: 1148-1156.

15. Wikenheiser MA, Markel MD, Lewallen DG, Chao EY (1995) Thermal response and torque resistance of five cortical half-pins under simulated insertion technique. J Orthop Res 13: 615-619.

16. Green SA (1990) Complications of pin and wire external fixation. Instr Course Lect 39: 219-228.

17. Ignacio R Arzac Ulla, Gustavo Fiorentini, Gonzalo Pérez Paz (2015) Osteotomía percutánea de Bösch. ¿El paciente acepta el clavo? Análisis clínico-funcional y resultados a corto plazo. Revista de la Asociacion Argentina de Ortopedia y Traumatología 80: 260-265.

18. Magnan B, Pezzé L, Rossi N, Bartolozzi P (2005) Percutaneous distal metatarsal osteotomy for correction of hallux valgus. J Bone Joint Surg Am 87: 1191-1199. 